\title{
O direito à educaçáo enquanto garantia de emancipaçáo humana para adolescentes e jovens privados de liberdade
}

\author{
Valdenir Batista Veloso \\ https://orcid.org/0000-0001-7959-8268
}

\section{Resumo}

Pensar sobre o direito à educação enquanto possibilidade de emancipação humana para adolescentes e jovens privados de liberdade não é uma tarefa simples numa sociedade contemporânea marcada pela globalização e pela exclusão, onde as forças de mercado têm, incessantemente, transformado as esferas da produçáo e do consumo, produzindo variadas formas de segregação e influenciando a subjetividade desses sujeitos, ainda ontologicamente inseguros quanto à constituição do ser social. Nesse ponto, é importante enaltecer que a não garantia de permanência do jovem na escola é uma das primeiras violaçóes de direitos dessa população. Desta forma, o presente artigo tem como intençáo discutir o papel do Estado na definição e estruturação das políticas públicas sociais, uma vez que tais políticas têm um papel fundante no desenvolvimento humano e na busca de condiçóes mínimas de uma vida digna para esses sujeitos. Clarifica-se que os sujeitos deste estudo sáo compostos por adolescentes e jovens em cumprimento de medida socioeducativa de internação nos Centros de Socioeducação do Paraná. Foi possível apontar, a partir dos dados levantados, que as práticas educativas dispensadas a esses sujeitos ainda acontecem num contexto de muita precariedade, pois o governo, tem relegado pouca atenção e prioridade para o sistema socioeducativo.

Palavras-chave: Direito à educação, Jovem em conflito com a lei, Socioeducação.

\section{The right to education as a warranty of human emancipation for adolescents and young people deprived of their liberty}

\section{Abstract}

Thinking about the right to education as a possibility of human emancipation for adolescents and young people deprived of freedom is not a simple task in a contemporary society marked by globalization and exclusion, where market forces have incessantly transformed the spheres of production and consumption, producing various forms of segregation and influencing the subjectivity of these subjects, still ontologically insecure about the constitution of social being.

\footnotetext{
${ }^{1}$ Doutorando da Escola de Educação e Humanidades da Pontifícia Universidade Católica do Paraná. Mestre em Educação pela UFPR na linha de pesquisa de Políticas Públicas Educacionais. Bacharel em Administração Pública pela UAB/UEPG. Licenciado em Pedagogia pela Universidade Federal do Paraná. Secretário Executivo dos Conselhos Setoriais do Governo do Paraná. E-mail: vbvufpr@hotmail.com.
} 
At this point, it is important to emphasize that the failure to guarantee the permanence of young people in school is one of the first violations of the rights of this population. Thus, this article intends to discuss the role of the State in defining and structuring social public policies, since such policies have a founding role in human development and in the search for minimum conditions of a dignified life for these subjects. It is clarified that the subjects of this study are composed of adolescents and youths in fulfillment of a socio-educational measure of internment in the Centers of Socio-education of Paraná. It was possible to point out, from the data collected, that the educational practices dispensed to these subjects still happen in a very precarious context, because the government has relegated little attention and priority to the socio-educational system.

Keywords: Right to education, Youth in conflict with the law, Socio-education.

\section{Introduçáo}

Inicialmente, clarifica-se que este artigo é parte de uma dissertação de mestrado em educação que teve como foco estudar a relação entre segregaçáo urbana, violência e o direito à educação de adolescentes e jovens em cumprimento de medida de internação.

Nesse ponto, destaca-se que esse estudo ganha relevância na medida em que a não garantia de permanência do jovem na escola é uma das primeiras violações de direitos desta população. Para tanto, basta verificar um dado do Relatório, edição 2015/2016, do Departamento Socioeducativo do Paraná, o qual aponta que quase $51 \%$ dos adolescentes e jovens em privação de liberdade náo estavam estudando quando apreendidos e encaminhados sistema socioeducativo. E, outros $15 \%$, estavam matriculados na rede regular, mas não a frequentavam, segundo aponta o mesmo relatório.

Por isso, é preciso analisar a juventude em conflito com a lei em sua totalidade, para além das aparências, procurando evidenciar mais as contradiçóes ora existentes do que as identidades não antagônicas que se fazem presentes, tendo em vista que a questáo da alteridade e da individualidade juvenil é completamente afetada por uma sociedade meritocrática, excludente e produtora de violências, ensejando pois alteraçóes importantes relacionadas à discussão de como deve ser a sociedade em que o jovem vive, se reproduz, se educa, onde vende a sua força de trabalho e onde convive socialmente. 
Estado, desigualdades sociais e políticas públicas para à infância e juventude

Inicialmente, destaca-se que o Estado não é algo abstrato, homogêneo e muito menos uniforme, pois nele existem diferentes grupos sociais cujos interesses não são plenamente coincidentes. O Estado é o cenário legítimo no qual acontece a confrontação de aspiraçóes, objetivos e projetos que expressam a diversidade constituinte na sociedade. Nessa perspectiva, pode-se dizer que o Estado é constituído a partir das relaçóes de força entre os grupos econômicos, políticos e a sociedade civil organizada. É, portanto, a partir das relaçóes de poder e do tensionamento desses grupos que as açóes do Estado são direcionadas, emergindo assim as políticas públicas.

Em sua análise sobre o Estado, Poulantzas (2000) descreve-o como resultado de uma relação de forças entre classes e fraçôes de classe, isto é, um "Estado-relação". Dessa forma, uma política de Estado favorável a um grupo " $\mathrm{x}$ " ou a um grupo " $y$ " num determinado momento, pode ser considerada resultante das próprias contradiçóes que se fazem presentes na estrutura do Estado. Nesse ponto, destaca-se que o Estado exerce o papel de coesão da sociedade, influenciando e sendo influenciado por fatores econômicos, ideológicos e políticos de cada época.

Aqui, é importante enaltecer ainda que, como já apontava Marx (1985), mesmo o Estado encontrando-se dominado pela burguesia, há, em suas estruturas, interesses das classes subalternas que também estarão representados. No entanto, os aparelhos hegemônicos que compóem a estrutura do Estado tendem a favorecer, de uma maneira ou de outra, a classe economicamente dominante, pois "em cada formação social específica a classe socialmente dominante, proprietária privada dos meios de produção e de subsistência, além de dominar o processo produtivo destes, domina, direta ou indiretamente, o Estado político a ela correspondente." (ANDRADE, 2012, p. 14)

Portanto, conforme preceitua Poulantzas (2000), uma classe social somente será hegemônica nessa sociedade quando assumir um "bloco de poder”, uma vez que não há a menor possibilidade de tal classe tornar-se hegemônica sem que esteja ao mesmo tempo no controle de um bloco de poder, tendo, por consequência, o condão de influenciar o Estado, pois a hegemonia de uma classe efetiva-se quando essa exerce a dominação sobre outras classes sociais e sobre a estrutura estatal. 
Assim sendo, tem-se um Estado que não está acima dos interesses privados, nem muito menos o que exerce o papel de representante do interesse geral de todas as classes, haja vista que esse Estado estará, sempre, subordinado à propriedade privada. A essência do Estado, enquanto fenômeno social, só pode ser compreendida a partir das relaçóes da sociedade específica na qual ele existe. Dessa forma, o Estado, outrora concebido, está condicionado pelas relaçóes que caracterizam a atual sociedade capitalista. Por isso, para compreender esse Estado é preciso, primordialmente, contextualizá-lo a partir da totalidade do sistema de produção e reprodução das relaçôes sociais determinadas pela conjuntura do capital.

Partindo-se desse Estado complexo em que se aliena o sujeito por meio da cooptação e de estratégias de pseudoparticipação e, ainda, onde as garantias fundamentais de cidadania (como os direitos civis, políticos e sociais) não estão plenamente efetivadas, não há como se falar em emancipação do cidadão sem abordar a questão da emancipação humana, pois desta decorre a desalienação total do ser humano, com o pleno acesso aos direitos de cidadania.

Mas, para o Estado moderno conforme foi concebido e em plena pujança neste século XXI, não há o menor interesse na desalienação total do cidadão, pois, conforme esclarecido na introdução deste texto, o Estado prefere efetivar parcialmente a emancipaçáo política do sujeito, pois essa emancipação garante a perpetuação dos elementos fundantes da sociedade civil burguesa, uma vez que as liberdades individuais asseguradas pelo Estado favorecem os interesses particulares próprios de cada sujeito, sem a devida preocupação com o coletivo, com os demais membros que compóem a comunidade. Esse processo perpetua a fragmentação social e aprofunda a alienação do indivíduo, o que se torna interessante para o Estado, o qual individualiza o sujeito, os seus direitos e as suas demandas.

O conceito de modernidade, tanto no Estado como na sociedade, existente hoje, é resultado do processo de mudanças sociais que houve ao longo dos séculos nas estruturas econômica, política, produtiva e institucional da sociedade. Dessa forma, o individualismo passou a ser a ideologia da sociedade moderna, isto é, o individualismo é um produto da sociedade e, nesse ponto, o que se ganha em liberdade se perde em solidariedade e coesão social. Semelhantemente, no atual contexto de superprodução e de superconsumo, em que o dinheiro se torna preponderante na aquisiçáo de 
bens, tal individualismo favorece, de uma maneira ou de outra, o Estado, que se afasta cada vez mais dos problemas sociais, tendo em vista que o conformismo e a despolitização emergem entre os indivíduos.

Destarte, Bauman (2001) enfatiza que o enfraquecimento do Estado, a perda de confiança na política tradicional, a desregulamentação das relaçóes de trabalho e a provisoriedade dos vínculos coletivos são características da denominada "modernidade líquida", onde as açóes individualizadas preponderam sobre as relaçóes coletivas.

Outrossim, verifica-se também que para além do discurso da globalização e da modernidade, atualmente denota-se o aumento da distância entre pobres e ricos, onde as diferenças são aprofundadas, o desemprego crescente torna-se cada dia mais crônico, as camadas médias da população perdem em qualidade de vida e o Estado social abre espaço para o Estado penal, com a consequente marginalização das comunidades periféricas.

Nesse sentido, Wacquant (2008) aponta para a transformação do papel do Estado, com a consequente precarização do trabalho e a desregulação social. O Estado torna-se mais liberal para o capital e para as classes abastadas e mais punitivo para as classes marginalizadas, isto é, "para com aqueles já desestabilizados seja pela conjunção da reestruturação do emprego com o enfraquecimento da proteção do Estado de Bem-estar social, seja pela reconversão de ambos em instrumentos para vigiar os pobres" (WACQUANT, 2008, p. 94).

Dessa maneira, torna-se mais difícil discutir direitos de jovens delinquentes nesta sociedade que impóe paradigmas dentro de uma lógica capitalista e de processos de marginalização e de invisibilidade social, acompanhados ainda de reiteradas situaçóes de desrespeito aos direitos humanos e da banalização da própria vida dos jovens.

Enfim, essa situação encontra-se ainda mais agravada com a aprovação da Proposta de Emenda à Constituição no 55/2016, denominada PEC do teto dos gastos públicos que congela os referidos gastos nas políticas sociais por um período de vinte anos. Dessa forma, tais políticas acabam por se constituir em terrenos férteis para a negociação de parcerias entre o Estado e o mercado, o qual oferece soluçóes aparentemente eficazes para a gestão das políticas sociais. Assim, a educação pública e as políticas sociais voltadas para a juventude e para as comunidades menos favorecidas acabam por se reduzir em açóes clientelistas e casuísticas de acordo com a lógica do mercado e do capital. 
Para Bourdieu (2012), a ausência do Estado e tudo o que disso decorre acaba por afetar parcelas significativas da sociedade, principalmente aquelas que já se encontram privadas de recursos econômico, cultural ou político e que dessa forma dependeriam do Estado para se chegar ao exercício da cidadania. Para tanto, a ausência de políticas públicas nesses locais, em que nem cidadania há, acaba por imperar a lógica do "cada um por si" e, consequentemente, o aumento considerável das situações de violência enquanto resposta social desses grupos, os quais reconhecem o Estado somente pelos aparelhos de força e de coerção.

Em matéria de políticas sociais isto tem um efeito interessante, pois a ausência de políticas democráticas voltadas para assegurar a justiça distributiva do direito de todas e de todos às garantias constitucionais diminuem o "tamanho" do Estado para com tais políticas, além de produzirem a desigualdade e a exclusão social. E, por sua vez, a negação desses direitos vivida pelos sujeitos produz uma hierarquização entre os mesmos, tornando-os extremamente desiguais. Já essa desigualdade expressa a transformação das diferenças em situaçóes de poder, de conflitos e de opressão aos grupos sociais mais vulneráveis. Pode-se afirmar, assim, que a desigualdade e a pobreza geram a exclusão social ao cercear o desenvolvimento do ser humano conforme os preceitos constitucionais.

Nesse ponto, percebe-se que o Estado, ao invés de elaborar e oferecer políticas sociais, direciona recursos para os aparelhos de repressão, uma vez que são mais eficazes do ponto de vista higienista, demonstrando claramente que a criminalidade está acompanhada da pobreza, dos baixos níveis de escolaridade e de renda, dentre outras mazelas da sociedade. Como aponta Kerstenetzky (2012), as políticas socioassistenciais são as que mais seguem subfinanciadas no Brasil, apesar dos avanços obtidos nos últimos anos com a regulamentação do Sistema Único de Assistência Social - SUAS, há uma considerável parcela de socialmente excluídos que ainda precisam estar nos orçamentos públicos.

Como resultado desse processo, verifica-se um crescimento da criminalização e da marginalidade, pois para se manter o controle social fazse necessário aumentar o efetivo policial, principalmente para atuaçáo em comunidades pauperizadas. Esse fenômeno, tipicamente urbano, afeta principalmente aquela faixa da população "constituída pelos que estão em situação de desemprego, subemprego ou pobreza. [...] Neste sentido, a 
distribuição espacial da pobreza dentro das cidades coincide sistematicamente com a da criminalidade" (COELHO, 1978, p. 140-148).

Deste modo, o tripé insegurança, criminalidade e pobreza é potencializado pela ausência do Estado, mais especificamente de políticas públicas sociais, pois nessa conjuntura o que se tem observado é que

[...] uma gestão judiciária e carcerária da pobreza é tanto mais provável e pronunciado quanto mais intensamente a política econômica e social implantada pelo governo do país considerado inspire-se em teorias neoliberais que levam à "mercantilização" das relaçôes sociais, e quanto menos protetor desde o início seja o Estado-providência em questão (WACQUANT, 2001, p. 141).

Face à dinâmica exposta, em uma sociedade balizada pelo consumo, pelo desemprego e pela pobreza, o que se tem observado é o aumento substancial da população carcerária, principalmente de adultos, sendo que o Brasil responde pela quarta maior população de presidiários do mundo, seguindo a lógica do encarceramento adotada em países como os Estados Unidos, China e Rússia. Tal cultura do cárcere tem gerado nos indivíduos:

[...] estigmatização, interrupção das estratégias escolares, matrimoniais e profissionais, desestabilização das famílias, supressão das redes sociais, enraizamento, nos bairros deserdados onde a prisão se banaliza, de uma "cultura de resistência", até mesmo de desafio, à autoridade, e todo o cortejo das patologias, dos sofrimentos e das violências (inter)pessoais comumente associadas à passagem pela instituição carcerária (WACQUANT, 2001, p. 143).

Os processos de estigmatização apontados por Wacquant (2001) também afetam os adolescentes e jovens em cumprimento de medida de internação, mesmo representando, aproximadamente, $3 \%$ da população carcerária brasileira, tais jovens sáo marcados por esse processo, com um condicionante mais gravoso, estão numa fase biológica e social do desenvolvimento. O referido autor salienta que a "delinquência juvenil" é alarmada pela mídia e pela ausência de estatísticas que comprovem o aumento desse fenômeno. Além disso, a reclusão desses jovens não acaba com as desigualdades sociais oriundas da atual sociedade de classes. 
Em função disso, fatores como as desigualdades sociais, a falta de oportunidades, a ausência de políticas públicas e a capilaridade do crime organizado contribuem para que adolescentes e jovens se envolvam em atos infracionais, ainda mais quando esses sujeitos convivem com determinadas circunstâncias sociais em que a reprodução da violência e da criminalidade são mais acentuadas, sendo que para além de protagonistas da violência, esses jovens são as maiores vítimas de um ciclo histórico de negação de direitos.

Sendo assim, fica notório que o Estado e suas políticas públicas já não podem ser explicados apenas do ponto de vista das suas estruturas de funcionamento, eles próprios exigem novas perspectivas de análise, que suportem a sua diversidade, complexidade e modernidade, e, consequentemente, levem em conta os sujeitos sociais e a sua mobilizaçáo social. Pois, os movimentos sociais organizados geram reflexos na sociedade e podem interferir na constituição de políticas públicas e no aparelho estatal como um todo.

Isso significa dizer que o estudo de políticas públicas, em especial as políticas sociais, neste começo de século XXI, requer que se lance mão de outros recursos metodológicos que não apenas aqueles que analisem as estruturas econômicas e sociais que perfazem o Estado, mas que também analise a importância de se pesquisar os sujeitos sociais fazedores e provocadores de políticas públicas como os movimentos sociais, os partidos políticos e os demais agentes diretamente ligados à constituição e à gestão das políticas públicas.

\section{O perfil econômico e social do jovem em conflito com a lei e os desafios do atendimento socioeducativo}

Conforme abordado nas páginas anteriores, as condiçôes socioeconômicas são preponderantes no desenvolvimento da vida dos sujeitos, principalmente quando se fala de adolescentes e jovens. A precariedade das condiçốes sociais da qual muitos adolescentes e jovens são vítimas propiciam a privação social, as desvantagens educacionais e as situaçôes de violência, muito típicas para esses sujeitos que vivem em ambientes de pobreza e de miséria. O histórico processo de constituição da política de atendimento socioeducativo é permeado por diversas contradiçóes que repercutem nas práticas socioeducativas realizadas no país. Assim, são inúmeros os desafios a 
serem superados para a implementação de um sistema de atendimento socioeducativo que tenha como garantia a promoção, proteção e defesa dos direitos humanos desses sujeitos.

A questão da juventude brasileira só pode ser compreendida a partir de uma análise detalhada dessa sociedade capitalista que gera desigualdades e, de igual forma, discutir os efeitos da pobreza nas condiçóes de vida dos adolescentes e jovens são primordiais para se poder questionar os atuais padróes sociais. Para Caldeira (2011), a rotina na vida de jovens das periferias é marcada pela constante injustiça e não por privilégios, por isso a importância de se debater a segregação e a desigualdade social.

No entanto, como se observou anteriormente, a atuação do Estado por meio das políticas sociais ainda está distante de transformar profundamente as condiçôes de vida de adolescentes e jovens, sobretudo quando oriundos de territórios mais vulnerabilizados. Nesse sentido, a luta pela ampliação das políticas sociais adquire um destaque fundamental, pois elas têm a finalidade de garantir o acesso a bens e serviços essenciais para essa parcela da população que se encontra em pleno processo de desenvolvimento e de construçáo da consciência cidadã.

Neste momento, cabe apresentar, no gráfico abaixo, o local de origem dos adolescentes e jovens que cumprem medidas socioeducativas no Paraná. Reiterando que os dados são oriundos do Relatório de Açóes do Departamento de Atendimento Socioeducativo do Paraná (2015/2016), do Relatório de visitas da Ordem dos Advogados do Brasil - Seção Paraná, 2015 e, do Levantamento Nacional do SINASE, realizado em 2013 e, publicizado em 2015.

Gráfico 1 - Município de residência dos adolescentes e jovens internos - Paraná

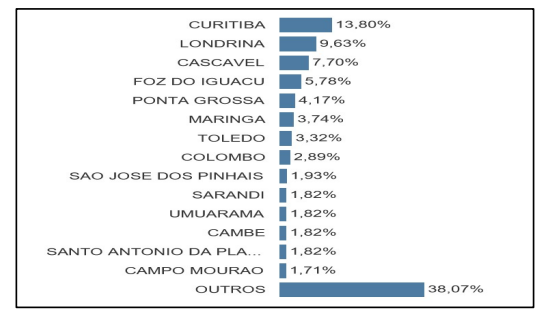

Fonte: Elaboração do autor, com base nos dados da pesquisa. 
Pelo que se observa no gráfico anterior, a maioria dos adolescentes que cometem atos infracionais no Paraná são oriundos de Curitiba, logicamente que prevalece o contingente populacional. Nessa lógica, a segunda maior cidade do estado também é, na mesma proporção, em número de adolescentes e jovens infratores. Destaca-se o percentual de Cascavel e Foz do Iguaçu, cidades fortemente marcadas pelo contrabando e pelo tráfico de drogas. Já as cidades de Colombo, Sarandi e Campo Mourão apresentam um alto índice de vulnerabilidade juvenil. Na categoria "outros", estão diversos municípios conurbados às cidades polo de cada regiáo, como representam um ou dois casos de adolescentes e jovens em conflito com a lei, torna-se inviável nominar todos esses municípios.

No que se refere à questão de vínculos familiares, pode-se observar nos dados que as famílias dos jovens em conflito com a lei são compostas por $4 \mathrm{a}$ 6 pessoas na maioria dos casos, cerca de $50 \%$. Portanto, o modelo clássico, ainda empregado em muitos estudos, de famílias pobres, numerosas e associadas à criminalidade está cada vez mais distante da realidade atual. $\mathrm{O}$ gráfico 2 apresenta uma dimensão dessa composição familiar.

Gráfico 2 - Composição familiar de adolescentes e jovens em medida de internação

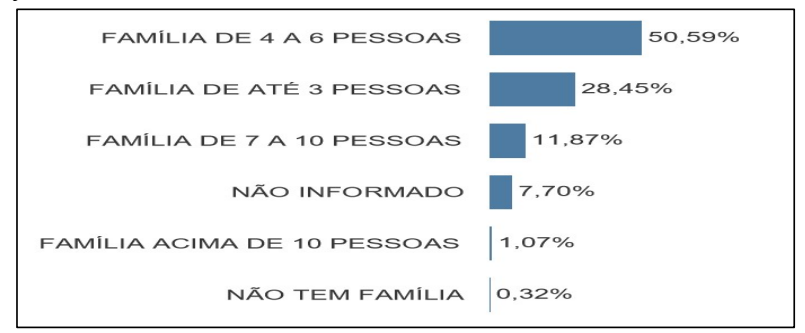

Fonte: Elaboração do autor, com base nos dados da pesquisa.

Ainda no âmbito da composiçáo familiar, outro achado importante refere-se ao percentual de adolescentes e jovens que moram somente com a mãe, isto é, aproximadamente $30 \%$ deles. Esse dado confirma a tendência brasileira de famílias chefiadas cada vez mais por mulheres. Outro ponto a se destacar neste quesito é o percentual superior a $10 \%$ de jovens que não moram 
nem com o pai e nem com a mãe, mas sim com outros familiares e/ou com a (o) companheira (o).

Para concluir a análise sobre questóes familiares, faz-se necessário verificar a renda familiar dos adolescentes e jovens em conflito com a lei, sendo que quase $52 \%$ deles vivem em famílias com renda entre um e dois saláriosmínimos, outros 8,5\% sáo oriundos de famílias que sobrevivem com menos de um salário-mínimo. E, apenas $1 \%$ destes jovens, provém de famílias com renda superior a cinco salários-mínimos.

$\mathrm{O}$ gráfico 3 ilustra com clareza essa questão da renda familiar dos internos do sistema socioeducativo paranaense.

Gráfico 3 - Rendimento familiar de adolescentes e jovens em medida de internação

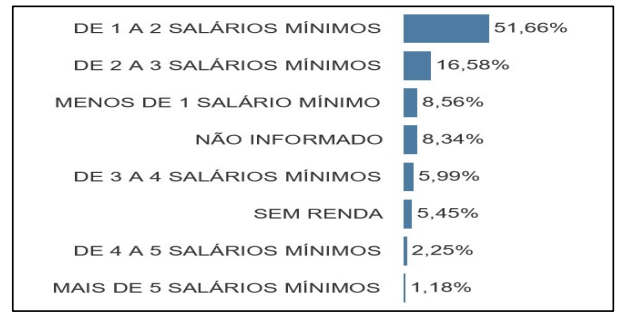

Fonte: Elaboração do autor, com base nos dados da pesquisa.

Nesse sentido, é importante resgatar a contribuição de Arretche (2015) sobre a questão salarial no Brasil, quando afirma que o "assalariamento" se consolidou nas famílias como uma importante fonte de renda. Essa afirmação é corroborada pelo IPEA (2016), o qual aponta que, em 2015, o rendimento médio mensal domiciliar no Brasil estava em $\mathrm{R} \$ 1.052,00$, isto é, cerca de cem reais a mais que o salário-mínimo em vigência no país. $\mathrm{E}$ ainda, não menos importante, destaca-se que embora tenha apresentado uma leve diminuição nos últimos anos, a baixa renda permanece entrelaçada com a baixa qualificação nos postos de trabalho.

Ao abordar a questáo do jovem em conflito com a lei e o acesso ao mundo do trabalho, percebe-se um alto percentual, praticamente $70 \%$ de jovens que náo estavam trabalhando no momento da apreensão e posterior internação. Apenas e tão somente $1 \%$ destes estava trabalhando devidamente registrado em carteira quando se envolveu com o ato infracional. 
Aqui é importante relembrar as dificuldades da juventude em acessar os postos de trabalho, quase três vezes mais do que um adulto, segundo a PNAD (2015). Essas dificuldades decorrem, muitas vezes, pela baixa escolarização, pela baixa qualificação ou por restrições impostas pelo mercado de trabalho. Da mesma forma, "além do desemprego aberto, há um desemprego oculto pelo desalento, isto é, há uma parcela dos jovens que não trabalham e desistiram de procurar emprego" (GONZALES, 2009, p. 115).

A discussão sobre relaçóes raciais é muito oportuna quando se trata do sistema socioeducativo paranaense e brasileiro, uma vez que os adolescentes e jovens em cumprimento de medida de internação são, em maior proporçáo, negros (pretos e pardos). Tanto na realidade paranaense, como no contexto nacional, os dados demonstram que $57 \%$ dos internos são pretos ou pardos. Como se trata de "autodeclaração" por parte do adolescente em relação à sua raça/cor, salienta-se, assim, que os efeitos sociais e simbólicos do preconceito racial podem ter interferido na declaração do interno, pois o imaginário social e midiático de pessoas brancas e de bem ou da "neymarização" " contribui para o processo de invisibilização da raça negra.

Em relação à idade dos adolescentes e jovens em conflito com a lei, tem-se a predominância de internos com idades entre 15 e 17 anos, sendo que a nível nacional esse número está na casa dos $67 \%$. No Paraná, a percentagem fica próxima dos $75 \%$ e, por sua vez, a população com idade entre 12 e 19 anos, segundo o IPARDES (2015), concentra-se em dois milhôes, ou, aproximadamente, $22 \%$ do total de paranaenses.

O discurso de que a reduçáo da maioridade penal é a solução para muitos problemas que afetam a coesão social não está ancorado em dados oficiais, pois o envolvimento de adolescentes e jovens com atos infracionais mais gravosos são mínimos, uma vez que a maioria dos casos está relacionado com furtos, roubos e tráfico de drogas. Nesse sentido, o levantamento nacional do SINASE (gráfico 4) aponta que 70\% dos infratores cometeram somente os atos infracionais considerados menos graves.

\footnotetext{
${ }^{2} \mathrm{O}$ termo neymarizaçáo, de elaboração do autor que subscreve este texto, é uma referência ao episódio que Neymar protagonizou quando ainda atuava pelo Santos Futebol Clube, em meados de 2013. Na ocasiáo, ao ser questionado por uma repórter se já havia sido vítima de racismo, Neymar respondeu: "Nunca. Nem dentro e nem fora de campo. Até porque eu nâo sou preto, né?”. Trazer esse episódio para a discussão sobre discriminação racial é importante, tendo em vista que Neymar é considerado um ídolo para muitos adolescentes e jovens, além de sua alta popularidade junto às redes sociais. Portanto, ao náo se identificar como preto ou pardo, Neymar jamais fará nenhuma apologia em referência à cultura negra.
} 
Gráfico 4 - Porcentagem de Adolescentes e Jovens por ato infracional - Brasil (2013)

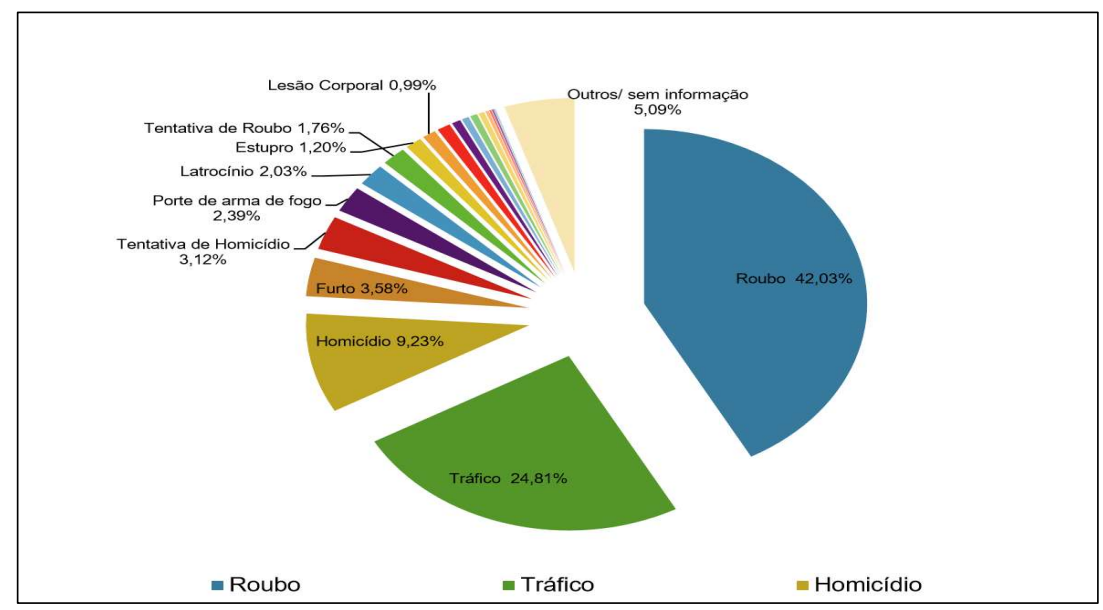

Fonte: SINASE (2013).

No Paraná, todos os adolescentes e jovens em cumprimento de medida de internação, segundo o relatório de ações 2015/2106 do Departamento Socioeducativo, possuem o Plano Individual de Atendimento, escolarização básica, qualificação profissional (24 cursos foram ofertados em 2015) e atividades de esporte, cultura e lazer (66 oficinas aconteceram durante o ano de 2015). As unidades possuem projetos pedagógicos, elaborados de acordo com as normativas educacionais em vigor. Já no que tange o acesso à saúde, as maiores unidades possuem médicos, odontólogos e enfermeiros e, nas unidades menores, os internos são encaminhados para os serviços da rede básica de saúde.

No entanto, apesar das informaçóes anteriores, derivadas do relatório de ações do Departamento Socioeducativo do Paraná (2015/2016), ainda se constata, em algumas unidades, a violação de direitos e o não cumprimento das diretrizes do SINASE. As figuras abaixo, oriundas do Relatório de visitas da $\mathrm{OAB} / \mathrm{PR}$ aos Centros de Socioeducação confirmam a proferida afirmação. 
Figura 1 - Alojamento no CENSE Curitiba com adolescentes descalços e colchão e cobertas ao chão
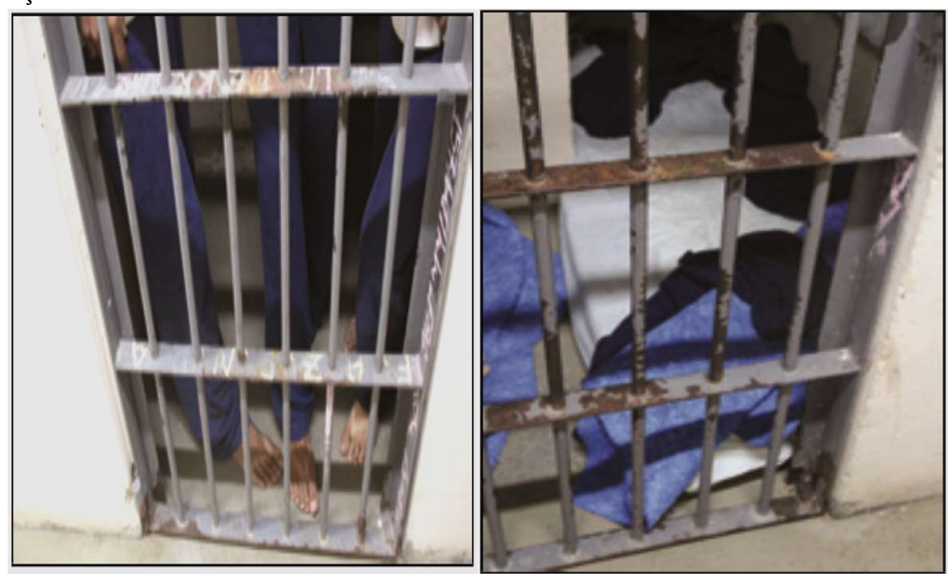

Fonte: OAB/PR (2015).

\section{O sistema socioeducativo e o direito à educaçáo}

Os elementos abordados ao longo das páginas anteriores possibilitaram uma compreensão, ainda que em caráter preliminar, de qual educação escolar se faz necessária para adolescentes e jovens em conflito com a lei. A função primordial do sistema socioeducativo está intimamente relacionada com o direito à educação, a não realizaçâo desse direito em espaços de privação de liberdade inviabiliza ao interno o acesso ao conhecimento científico historicamente acumulado. Para além do conhecimento, a educação deve possibilitar a análise crítica da sociedade, desvelando as contradiçóes que impedem o adolescente e o jovem em conflito com a lei de compreenderem a realidade da qual são vítimas.

Para além de discutir o direito à educação, faz-se necessário conhecer a trajetória educacional pregressa de adolescentes e jovens em conflito com a lei. De maneira geral, pode-se inferir que o nível de escolaridade da maioria desses jovens encontra-se concentrada no ensino fundamental, resultado das dificuldades de acesso e de permanência na escola, muitas vezes marcadas por sucessivas reprovaçóes e pela evasão escolar. Com isso, uma parcela 
considerável de adolescentes e jovens adentram o sistema socioeducativo marcados por uma elevada defasagem educacional. Nesse sentido, Dayrell, Carrano e Maia (2014) enfatizam que a trajetória escolar de muitos jovens "empobrecidos" está demarcada pelas contradiçôes de uma estrutura social excludente, as quais interferem significativamente nas possibilidades de vivência da condição juvenil.

Ao analisar a situação educacional de adolescentes e jovens em cumprimento de medida de internação no Brasil, tem-se um elevado percentual de distorção idade-série e de evadidos do sistema escolar, uma quantidade ínfima de internos que frequentavam o ensino médio e, ainda, um significativo número de não alfabetizados. Em relação ao analfabetismo, o relatório do Conselho Nacional de Justiça - CNJ (2012) identificou um percentual de $8 \%$ de internos não alfabetizados, com uma imensa variação regional em tal percentagem, pois enquanto na Região Nordeste $20 \%$ eram analfabetos, na Região Sul os internos na mesma situação representavam 1\% (no Paraná totalizavam 1,82\% em 2015).

No que diz respeito à distorção idade-série, o relatório do $\mathrm{CNJ}$ aponta que os adolescentes e jovens interrompem os estudos, em média, aos 14 anos de idade, sendo que $86 \%$ deles estava cursando a segunda fase do ensino fundamental no momento da apreensão. Esse dado, de quase $90 \%$, permite superar o estereótipo de que todo adolescente ou jovem em conflito com a lei não estuda, apesar de evidenciar a problemática da distorção idade-série que envolve esses sujeitos.

Os números anteriormente apresentados são suficientes para justificar o percentual ínfimo de adolescentes e jovens em conflito com a lei que estáo cursando o ensino médio. Enquanto o relatório do CNJ aponta para uma taxa de $11 \%$ de internos matriculados nessa etapa da escolarização básica, no Paraná esse percentual correspondia a menos de 5\% em 2015. Aqui é importante mencionar que essa taxa já esteve em quase 10\% em 2010.

Diante desses números, ainda que pouco significativos no total de matrículas nos CENSES, é preciso discutir se a redução desse percentual de matrículas no ensino médio tem relação com a diminuição de professores que deixaram de atuar nas unidades socioeducativas a partir de 2011, uma vez que como o número de matrículas nessa etapa de ensino é significativamente menor, o Governo do Estado pode não ter priorizado novas contrataçóes de 
docentes para atender os poucos internos que acessam a referida etapa, negligenciando o direito à educação de adolescentes e jovens.

Nesse quesito, é importante observar que o Estado, por meio do relatório de açôes 2015/2016 do Departamento Socioeducativo, não evidencia as estratégias utilizadas para ampliar o acesso ao ensino médio aos internos, fazendo somente uma menção de que 140 adolescentes e jovens realizaram as provas do Exame Nacional de Ensino Médio - ENEM em 2015, no entanto, não especifica se houve aprovaçôes para garantir a certificação do ensino médio para os referidos internos. Obviamente que se torna mais econômico para o governo incluir os adolescentes e jovens em privação de liberdade para que realizem o ENEM, ao invés de se investir na ampliação do quadro de docentes, principalmente para as disciplinas específicas do ensino médio, mesmo que seja para atender um número ínfimo de internos que estão aptos a cursarem mais essa etapa da educação básica.

\section{(In) Conclusóes}

Para enfrentar as situaçóes de exclusão social ainda presentes na sociedade brasileira, vários esforços foram empreendidos pelos governos e por segmentos da sociedade civil organizada na implementação de políticas públicas mais inclusivas. Ao longo da história brasileira vários estatutos legais foram elaborados e regulamentados com o objetivo de eliminar o assistencialismo nas políticas sociais, tais como os Sistemas Únicos de Saúde e da Assistência Social. No que se refere à infância e à juventude, o Estatuto da Criança e do Adolescente e o Sistema Nacional de Atendimento Socioeducativo vieram apresentar um alento a essa área. No entanto, para adolescentes e jovens em conflito com a lei ainda perduram práticas e concepçóes que criminalizam esses sujeitos e os territórios pauperizados dos quais a maioria é oriunda, cabendo ao Estado penal-policial prestar o "atendimento" aos desvalidos e aos desviantes das normas de coesão social.

$\mathrm{O}$ adolescente e o jovem em conflito com a lei, além de políticas públicas sociais, necessitam de uma abordagem educativa diferenciada e emancipadora. Este estudo, em sua simplicidade, contribuiu para identificar a complexidade que envolve o trabalho com os infratores e a necessidade de um sistema educacional e socioeducativo que possibilitem a ressocializaçáo desses sujeitos e os identifiquem como sujeitos de direitos. De igual forma, 
pode-se constatar que a adolescência e a juventude são duas categorias sociais que não podem ser apenas explicadas pela idade, mas por diversos fatores históricos e sociais. "Nesse âmbito, reiterar a noção de juventude nas pesquisas e nas açôes públicas é uma forma de dar visibilidade às questôes, demandas e necessidades dos jovens, entendidos de uma forma mais ampla" (DAYRELL; CARRANO e MAIA, 2014, p. 109).

No Paraná, a realidade educativa dos adolescentes e jovens em conflito com a lei sofreu mudanças significativas após o surgimento do SINASE, com a respectiva contratação de novos funcionários, reformas de unidades e inauguração de outras sob um viés arquitetônico mais humanizado, capacitaçóes para todos os profissionais atuantes no sistema socioeducativo e a seleção de professores para o atendimento educacional dos internos em todas as disciplinas da matriz curricular da educação básica. Nesse período, também se observa a nova concepção pedagógica adotada pelo Estado para o atendimento aos internos, com a implantação do Programa de Educação das Unidades Socioeducativas, que estabeleceu uma educação emancipadora não enciclopédica, que possibilitasse aos adolescentes e jovens o exercício da cidadania.

Em que pese as políticas de educação e da socioeducação, houve, a partir de 2011, uma descontinuidade de programas e políticas implementadas pela gestão do governador Roberto Requião (2003-2010), como a extinção de departamentos e coordenaçóes (embora tenham aumentando os cargos em comissão), a redução dos programas de formação continuada, o sucateamento das escolas públicas e dos centros de socioeducação, o aumento das contrataçóes via processo seletivo simplificado, o confisco dos recursos do Fundo para a Infância e Adolescência - FIA/PR, entre outras.

$\mathrm{O}$ que se tem notado no governo paranaense é a acentuada desresponsabilização do Estado na gestão das políticas sociais, derivada de um projeto conservador de sociedade que tem afetado todos os direitos sociais e as condiçóes de vida da classe trabalhadora, uma vez que o comprometimento do Estado é com a garantia da valorização do capital, fato esse que compromete as possibilidades de implementação de políticas públicas de acordo as necessidades sociais.

Para findar, destaca-se que garantir o direito à educação para uma juventude vitimizada pela ausência de um governo que náo priorizou políticas públicas para o desenvolvimento pessoal e para o acesso à cidadania desses 
sujeitos torna-se um desafio, pois o Estado só pode ser considerado democrático e de direito se promover a cidadania de todos os indivíduos, independentemente se os mesmos estiverem ou não em condição de cárcere.

\section{Referências}

ANDRADE, Mariana A. De Marx a Mészáros: A inseparável relação entre o Estado e a reprodução do capital. In: MELO, Edivânia; ANDRADE, Mariana A.; PANIAGO, Maria Cristina S. (Org.). Marx, Mészáros e o Estado. São Paulo: Instituto Lukács, 2012.

ARRETCHE, Marta (Org.). Trajetória das Desigualdades. Como o Brasil mudou nos últimos cinquenta anos. São Paulo: Editora Unesp, 2015.

BAUMAN, Zygmunt. Modernidade líquida. Rio de Janeiro: Editora Jorge Zahar, 2001.

BOURDIEU, Pierre (Coord.). A miséria do mundo. 9. ed. Petrópolis, RJ: Editora Vozes, 2012.

BRASIL. Secretaria Especial dos Direitos Humanos. Sistema Nacional de Atendimento Socioeducativo - SINASE. Brasília: CONANDA, 2006.

CALDEIRA, Teresa P. R. Cidade de muros. Crime, segregação e cidadania em São Paulo. São Paulo: Editora 34, Edusp, 2011.

COELHO, Edmundo C. A criminalização da marginalidade e a marginalização da criminalidade. Revista de Administração Pública, Rio de Janeiro: Fundação Getúlio Vargas, n. 2, abr./jun. 1978.

CONSELHO NACIONAL DE JUSTIÇA. Panorama Nacional: A execução das medidas socioeducativas de Internação. Conselho Nacional de Justiça, 2012. Disponível em: <http://www.cnj.jus.br/images/programas/justica-ao jovem/panorama_nacional_justica_ao_jovem.pdf.>. Acesso em: 13 ago. 2016.

DAYRELL, Juarez; CARRANO, Paulo; MAIA, Carla L. (Orgs.). Juventude e Ensino Médio: sujeitos e currículos em diálogo. Belo Horizonte: Editora UFMG, 2014. 
GONZALEZ, Roberto. Políticas de emprego para jovens: entrar no mercado de trabalho é a saída? In: CASTRO, Jorge A.; AQUINO, Luseni M. C.; ANDRADE, Carla C. (Orgs.). Juventude e Politicas Sociais no Brasil. Brasília: IPEA, 2009.

KERSTENETZKY, Celia L. O estado do bem-estar social na idade da razáo. Rio de Janeiro: Editora Elsevier, 2012.

MARX, Karl. O capital: crítica da economia política. 2. ed. São Paulo: Nova Cultural, 1985. Livro I. tomo II.

PARANÁ. Relatório de Açóes do Departamento de Atendimento Socioeducativo. Secretaria de Estado da Justiça, Cidadania e Direitos Humanos. Curitiba: DEASE, 2016.

POULANTZAS, Nicos. O Estado, o poder, o socialismo. São Paulo: Editora Paz e Terra, 2000.

WACQUANT, Loic. As duas faces do gueto. São Paulo: Boitempo Editorial, 2008.

. As Prisóes da Miséria. Rio de Janeiro: Editora Jorge Zahar, 2001.

Recebido em: 20 ago. 2020

Aceito em: 18 set. 2020 